\title{
Does $\beta$ adrenergic blockade influence the prognostic implications of post-myocardial infarction exercise testing?
}

\author{
DONAL P MURRAY, LIP BUN TAN, MAHMOOD SALIH, \\ PETER WEISSBERG, R GORDON MURRAY, WILLIAM A LITTLER \\ From the Department of Cardiovascular Medicine, University of Birmingham, East Birmingham Hospital, \\ Birmingham
}

SUMMARY The influence of $\beta$ blockade on the ability of ST depression, during pre-discharge exercise testing, to predict coronary anatomy and subsequent complications was studied in 300 consecutive post-infarct patients, 125 of whom underwent cardiac catheterisation. At the time of exercise 62 patients were taking a $\beta$ blocker. The exercise test had a higher sensitivity in predicting? multivessel disease in patients who were not taking $\beta$ blockers than in patients who were $(95 \%$ v. $76 \%$ ). $\beta$ Blockade did not, however, influence the ability of the test to identify patients at risk of subsequent cardiac events (sensitivity $84 \%$ and $85 \%$ respectively).

These results suggest that it is not necessary to stop treatment with $\beta$ blockers before pre-po discharge exercise testing of patients who have had an acute myocardial infarction.

The value and limitations of pre-discharge exercise testing in predicting the extent of coronary artery disease $^{1-3}$ and in identifying both high and low risk patients after acute myocardial infarction are well established. ${ }^{46}$ When exercise testing is carried out for diagnostic purposes, however, it has been suggested that $\beta$ adrenergic blockade may reduce the ability of the test to identify patients with clinically significant coronary artery disease. ${ }^{7-9}$ After myocardial infarction many patients are treated with $\beta$ blockers but, to date, the impact of $\beta$ blockade on the results of postinfarct exercise testing has not been studied.

We investigated whether treatment with $\beta$ blockers influenced the ability of pre-discharge exercise testing to identify those with multivessel disease or those at risk of subsequent cardiac events after a myocardial infarction.

\section{Patients and methods}

\section{PATIENTS}

Over an 18 month period all patients aged less than 66 years with electrocardiographic and enzymatic

Requests for reprints to Dr Donal P Murray, Department of Cardiovascular Medicine, John Radcliffe Hospital, Headington, Oxford OX3 9DU.

Accepted for publication 27 July 1988 evidence of acute myocardial infarction who survived to discharge from our coronary care unit were considered for pre-discharge exercise testing. ${ }^{10}$ W did not test patients with uncontrolled angina pec $\overrightarrow{\hat{O}}$ toris or cardiac failure, those with other serious cardiac or non-cardiac disease which would limie ability to exercise or affect short term prognosis, and? patients who were unwilling to perform an exercise test.

ELECTROCARDIOGRAPHIC CHANGES

A diagnosis of myocardial infarction was based on then development of new $Q$ waves or the evolution of ST$T$ wave changes on the electrocardiogram in association with either a typical history of chest pain persisting for at least 30 minutes or a rise in thes concentration of aspartate transaminase or lactic. dehydrogenase to twice the upper limit of normal $N$ The site of infarction was determined from thon resting electrocardiogram in the following way: in anterior infarction changes were seen in leads $\mathrm{V} 1-\mathrm{\omega}$ V5, in lateral infarction in leads V6, I, and aVL, and in inferior infarction in leads II, III, and aVF.

All exercise tests were performed on a treadmilf according to a modified Naughton's protocol. ${ }^{11} \mathrm{~A} 12^{-}$ lead electrocardiogram, blood pressure, and heart rate were recorded at rest and at one minute intervalso throughout the test. After the test, data were recor $\frac{\vec{D}}{\mathrm{D}}$ ded every two minutes up to 10 minutes. 
Exercise stopped at 18 minutes (equivalent to seven multiples of resting energy expenditure) or earlier if the patient developed limiting symptoms, ventricular arrhythmias, profound ST segment depression $(>4 \mathrm{~mm}$ ), or a fall in systolic blood pressure $>20 \mathrm{~mm} \mathrm{Hg}$. ST segment depression $\geqslant 1 \mathrm{~mm}$ at $80 \mathrm{~ms}$ from the $J$ point of the QRS complex on three consecutive beats, in lead groupings remote from the site of infarction was taken to indicate reversible ischaemia and disease in vessels other than the infarct related vessel-that is multivessel disease. The absence of ST depression on exercise was taken to imply disease confined to the infarct site only.

\section{CARDIAC CATHETERISATION}

All patients with exercise induced ST segment depression, symptoms suggestive of angina pectoris, and those aged less than 45 years were offered cardiac catheterisation. Selective coronary arteriography was performed six weeks after discharge from hospital by the Judkins technique. The catheter data were analysed without knowledge of the electrocardiographic data. A reduction in luminal diameter of $\geqslant 50 \%$ at angiography was regarded as indicating haemodynamically significant stenosis. ${ }^{212}$ Patients were designated as having single vessel disease if a significant stenosis was found in only one of the three main coronary arteries and as having multivessel disease if there was a significant stenosis in more than one of the three main arteries or a stenosis in the left main coronary artery.

The exercise test results were related to findings at coronary arteriography: remote ST depression in association with multivessel disease signified a true positive result and ST depression in association with disease confined to the infarct related vessel signified a false positive result. Single vessel disease confined to the infarct related vessel with no associated ST depression indicated a true negative result, while multivessel disease with no associated ST depression indicated a false negative result.

\section{CLINICAL END POINTS}

All patients were followed up in our cardiology clinic for a mean (SD) of 12 (3) months. During this time the occurrence of the following events was noted: (a) death; (b) recurrent myocardial infarction; (c) heart failure (this was defined as the need to introduce or increase antifailure treatment); (d) severe angina pectoris (this was defined as the need to introduce specific antianginal medication in addition to $\beta$ blockers); metoprolol (100 $\mathrm{mg}$ twice daily) was prescribed routinely to all patients after completion of their exercise test unless clinically contraindicated; $(e)$ coronary bypass grafting or per- cutaneous transluminal angioplasty (these were performed for angina pectoris that was unresponsive to medical treatment or for asymptomatic disease of the left main coronary artery (one patient)).

Some patients had more than one cardiac event during the follow up period. Therefore, the number of patients who suffered one or more cardiac events was noted. As death and reinfarction are the two most important cardiac events the number of patients with these major complications was also noted.

Exercise test results were related to clinical outcome. In this context, ST depression in a patient who experienced at least one subsequent cardiac event indicated a true positive result while ST depression in a patient who did not experience any cardiac event during the follow up indicated a false positive result. A true negative result indicated a patient who had neither ST depression on exercise nor any subsequent cardiac events, while a false negative result indicated a patient who did not have ST depression on exercise but did experience at least one cardiac event on follow up.

\section{STATISTICAL ANALYSIS}

Student's $t$ test was used to assess differences between the means of independent observations. The $\chi^{2}$ test was used to assess differences between proportions. A p value $<0.05$ was regarded as statistically significant. Values are given as mean (SD).

\section{Results}

Three hundred and fifty patients were considered for exercise testing over an 18 month period. Fifty did not perform a pre-discharge exercise test: 38 because of heart failure, seven because of the presence of other serious medical conditions, three because of

Table 1 Background clinical variables and exercise test variables (mean (SD)) in patients treated with $\beta$ blockers and those who were not

\begin{tabular}{|c|c|c|c|}
\hline & $\begin{array}{l}\text { B Blocker } \\
(n=62)\end{array}$ & $\begin{array}{l}\text { No B blocker } \\
(n=238)\end{array}$ & $\begin{array}{l}95 \% \text { Confidence } \\
\text { intervals }\end{array}$ \\
\hline $\begin{array}{l}\text { Age (yr) } \\
\text { Males } \\
\text { Norris index } \\
\text { AST (SI units) } \\
\text { LDH (SI units) }\end{array}$ & $\begin{array}{c}53(8 \cdot 2) \\
45(72 \%) \\
4 \cdot 2(1 \cdot 4) \\
149(88) \\
1518(847)\end{array}$ & $\begin{array}{c}53(4 \cdot 6) \\
176(74 \%) \\
4.5(1 \cdot 4) \\
171(86) \\
1534(728)\end{array}$ & $\begin{array}{l}-3.8 \text { to }+4 \cdot 2 \\
-10 \% \text { to }+14 \% \\
-0.7 \text { to }+1 \cdot 3 \\
-2 \text { to }+46 \\
-14 \text { to }+46\end{array}$ \\
\hline $\begin{array}{l}\text { Infarct site: } \\
\text { Anterior } \\
\text { Inferior } \\
\text { Other } \\
\text { Q wave infarction } \\
\text { Exercise duration } \\
\text { (min) }\end{array}$ & $\begin{array}{r}27(44 \%) \\
28(45 \%) \\
7(11 \%) \\
47(76 \%) \\
10 \cdot 4(3.3)\end{array}$ & $\begin{array}{c}100(42 \%) \\
120(50 \%) \\
18(8 \%) \\
167(70 \%) \\
10 \cdot 7(3 \cdot 2)\end{array}$ & $\begin{array}{l}-16 \text { to }+16 \\
-15 \text { to }+20 \\
-25 \text { to }+18 \\
-14 \text { to }+10 \\
-0.8 \text { to }+1 \cdot 4\end{array}$ \\
\hline ST depression (mm) & $2.2(0.9)$ & $2 \cdot 6(1 \cdot 1)$ & -0.4 to +0.6 \\
\hline
\end{tabular}

AST, Aspartate aminotransferase; LDH, lactic dehydrogenase. 
Table 2 Prognostic implications of ST depression induced during exercise testing when cardiac events were grouped together and when patients were subdivided on the basis of treatment or with $\beta$ blockers at the time of exercise

\begin{tabular}{|c|c|c|c|c|c|}
\hline \multirow[t]{2}{*}{$\begin{array}{l}\beta \text { Blockers (62) } \\
\text { No } \beta \text { blockers }(238)\end{array}$} & $\begin{array}{l}\text { True + } \\
16(26 \%) \\
95(40 \%)\end{array}$ & $\begin{array}{l}\text { True - } \\
32(52 \%) \\
90(38 \%)\end{array}$ & \multicolumn{2}{|c|}{$\begin{array}{l}\text { False + } \\
11(18 \%) \\
36(15 \%)\end{array}$} & $\begin{array}{r}\text { False - } \\
3(5 \%) \\
17(7 \%)\end{array}$ \\
\hline & $\begin{array}{l}\beta \text { Blocker } \\
(n=62) \\
(\%)\end{array}$ & \multicolumn{2}{|c|}{$\begin{array}{l}\text { No } \beta \text { blocker } \\
(n=238) \\
(\%)\end{array}$} & \multicolumn{2}{|c|}{$\begin{array}{l}95 \% \text { Confidence } \\
\text { intervals } \\
\%\end{array}$} \\
\hline $\begin{array}{l}\text { Sensitivity } \\
\text { Specificity } \\
\text { Predictive accuracy } \\
\text { Positive predictive valu } \\
\text { Negative predictive } \\
\text { value }\end{array}$ & $\begin{array}{r}84 \\
74 \\
77 \\
59 \\
91\end{array}$ & $\begin{array}{l}85 \\
71 \\
77 \\
73 \\
84\end{array}$ & & $\begin{array}{l}-17 \\
-20 \\
-10 \\
-6 \\
-10\end{array}$ & $\begin{array}{l}\text { to }+19 \\
\text { to }+14 \\
\text { to }+9 \\
\text { to }+34 \\
\text { to }+20\end{array}$ \\
\hline
\end{tabular}

practical difficulties, and two refused to exercise. Of the 300 patients who were exercised 158 had ST segment depression on exercise. The mean age of the exercised patients was 53 years (range 28-65 years). The male/female ratio was $5 \cdot 4: 1$.

\section{$\beta$ BLOCKADE}

At the time of exercise 62 of the 300 patients were already taking a $\beta$ blocker; 42 patients had been started on a $\beta$ blocker in the early stages of acute myocardial infarction, 13 had been taking $\beta$ blockers before infarction, and seven had been started on treatment after their infarct because of angina pectoris (four) or hypertension (three). Of the 158 patients with ST depression, 27 were taking a $\beta$ blocker at the time of exercise and 131 were not. In those who were being treated with $\beta$ blockers and those who were not age, sex, Norris index, enzymatically estimated infarct size, and infarct site were similar (table 1). The two groups exercised for a similar length of time $(10.4(3.3)$ and 10.7 (3.2) minutes respectively) and had a similar degree of ST depression (2.2 (0.9) and $2.6(1.1) \mathrm{mm}$ respectively). Thirty seven per cent of those on $\beta$ blockers and $45 \%$ of those who were not developed angina pectoris on exercise testing $\left(\chi^{2}=1 \cdot 1 ; \mathrm{NS}\right)$.
Murray, Tan, Salih, Weissberg, Murray, Littler CLINICAL OUTCOME

During the follow up period $131(44 \%)$ of the $300 \Rightarrow$ patients had at least one cardiac event. Twenty four $\stackrel{5}{+}$ suffered recurrent myocardial infarction and 11 of $\mathrm{C}$ them died. A further three patients died without $\frac{\bar{F}}{\bar{N}}$ evidence of reinfarction. Thus 27 patients died or had $\frac{\sigma}{\sigma}$ reinfaction. One hundred and fifteen $(38 \%) \propto$ developed angina pectoris, $38(13 \%)$ developed car- $๗$ diac failure, and 39 patients $(13 \%)$ had coronary $\vec{\circ}$ bypass surgery or percutaneous angioplasty. Some patients are included in more than one category.

\section{RELATION OF EXERCISE TEST RESULTS TO OUTCOME}

One hundred and fifty eight of the 300 patients had $\sigma$ ST segment depression on exercise. Table 2 shows that when all cardiac events were grouped together $\beta$ adrenergic blockade at the time of exercise testing did $\triangle$ not influence the ability of the test to identify patients at risk of subsequent complications. When cardiac $\Phi$

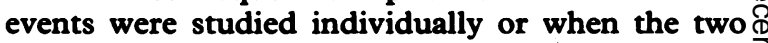
major events (death and reinfarction) were taken $\bar{\sigma}$ together it was again apparent that $\beta$ blockade did not $\stackrel{\Phi}{-}$ influence the test sensitivity (table 3 ).

\section{RELATION OF EXERCISE TEST RESULTS TO CORONARY ANATOMY}

A total of 125 patients underwent cardiac catheterisation, 90 because of exercise induced ST segment depression and 35 for other reasons-symptoms $\frac{\circ}{\varnothing}$ suggestive of myocardial ischaemia (29) or age less $\varrho$ than 40 years (six). Seventy three $(81 \%)$ of patients $\overrightarrow{\vec{O}}$ with ST segment depression and eight $(23 \%)$ of 353 patients without ST depression had multivessel disease $\left(\chi^{2}=62.0, p<0.001\right)$. Twenty seven of the 125 catheterised patients were taking a $\beta$ blocker at the time of exercise. Twenty one $(77 \%)$ of the $27 \stackrel{\varrho}{~}$ patients taking $\beta$ blockers and $60(61 \%)$ of the 98 who were not had multivessel disease. Five $(19 \%)$ of the 3 . 27 patients taking $\beta$ blockers had false negative $\delta$ exercise tests compared with three $(3 \%)$ of the 98 not taking $\beta$ blockers $\left(\chi^{2}, 6 \cdot 1 ; p<0 \cdot 05\right)$. As a result, the 0

Table 3 Sensitivity of ST depression in predicting individual cardiac events when patients were subdivided on the basis of treatment with $\beta$ blockers at the time of exercise

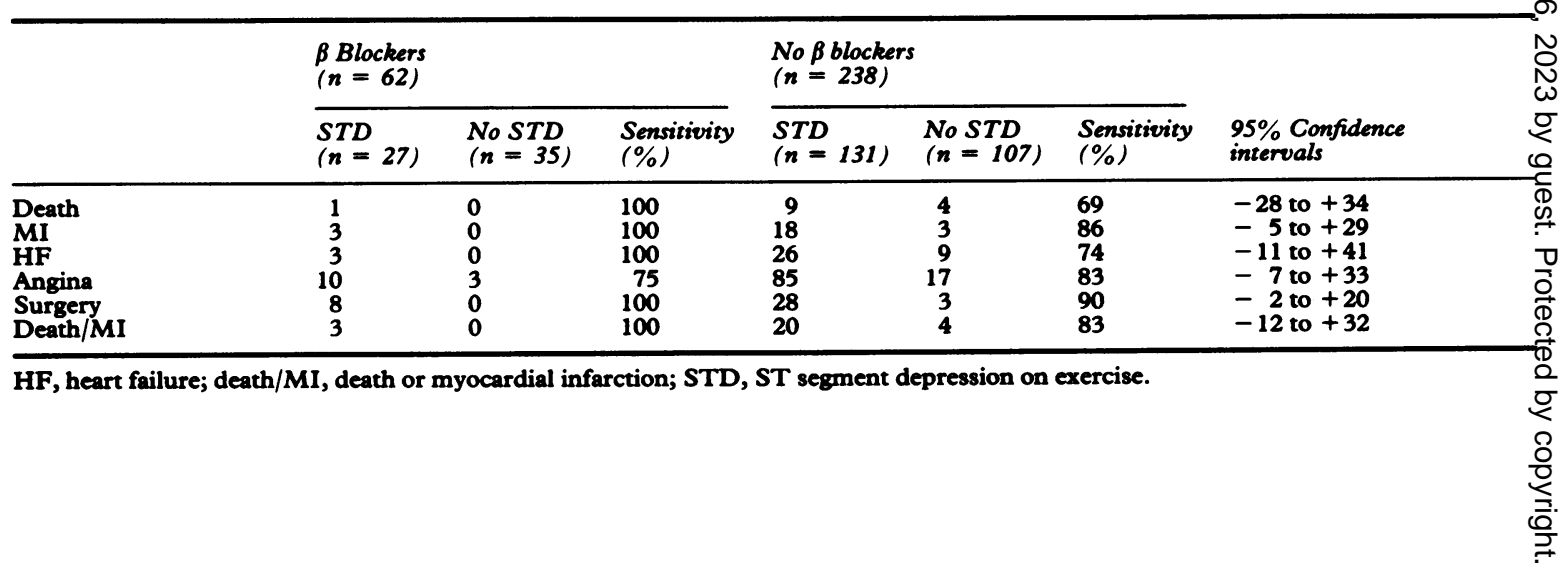


Table 4 Ability of ST depression induced by exercise to predict multivessel disease when patients were subdivided on the basis of treatment with $\beta$ blockers at the time of exercise

\begin{tabular}{|c|c|c|c|c|c|}
\hline \multirow[t]{2}{*}{$\begin{array}{l}\text { B Blockers (27) } \\
\text { No B blockers (98) }\end{array}$} & $\begin{array}{l}\text { True + } \\
16(59 \%) \\
57(58 \%)\end{array}$ & $\begin{array}{c}\text { True - } \\
4(15 \%) \\
23(23 \%)\end{array}$ & \multicolumn{2}{|c|}{$\begin{array}{c}\text { False + } \\
2(7 \%) \\
15(15 \%)\end{array}$} & $\begin{array}{l}\text { False - } \\
5(19 \%) \\
3(3 \%)\end{array}$ \\
\hline & $\begin{array}{l}\beta \text { Blocker } \\
(n=27) \\
(\%)\end{array}$ & \multicolumn{2}{|c|}{$\begin{array}{l}\text { No } \beta \text { blocker } \\
(n=98) \\
(\%)\end{array}$} & \multicolumn{2}{|c|}{$\begin{array}{l}95 \% \text { Confidence } \\
\text { intervals } \\
\%\end{array}$} \\
\hline $\begin{array}{l}\text { Sensitivity } \\
\text { Specificity } \\
\text { Predictive accuracy } \\
\text { Positive predictive valu } \\
\text { Negative predictive } \\
\text { value }\end{array}$ & $\begin{array}{r}76 \\
67 \\
74 \\
89 \\
44\end{array}$ & $\begin{array}{l}95 \\
61 \\
82 \\
79 \\
88\end{array}$ & & $\begin{array}{r}0 \\
-35 \\
-\quad 1 \\
-7 \\
+\quad 9\end{array}$ & $\begin{array}{l}\text { to }+38^{\star} \\
\text { to }+47 \\
\text { to }+17 \\
\text { to }+27 \\
\text { to }+79 \star\end{array}$ \\
\hline
\end{tabular}

result, the exercise test had a higher sensitivity $(95 \%$ v $\left.76 \% ; \chi^{2}, 4.25 ; \mathrm{p}<0.05\right)$ and a higher negative predictive value $\left(88 \% v 44 \% ; \chi^{2}, 5.06 ; \mathrm{p}<0.05\right)$ in predicting coronary anatomy in patients who were not taking $\beta$ blockers than in those who were (table 4). The test had a similar specificity, predictive accuracy, and positive predictive value in the two groups of patients.

\section{RELATION OF CORONARY ANATOMY TO}

PROGNOSIS

Fourteen of the 125 catheterised patients died or reinfarcted. The three patients who were taking $\beta$ blockers and had such major events had both ST depression on exercise and multivessel disease, as did 10 of the 11 patients who were not taking $\beta$ blockers and who died or reinfarcted (figure). None of the catheterised patients with single vessel disease had a major complication.

\section{Discussion}

$\beta$ Adrenergic blocking agents can reduce or delay the onset of angina pectoris and ST segment depression on exercise testing. ${ }^{7-9}$ Consequently, if $\beta$ blockers are used after myocardial infarction, either as antianginal treatment or exclusively for secondary prevention, most physicians avoid prescribing them before the patient has a pre-discharge exercise test. However, many patients will have been receiving $\beta$ blockers before their infarct and such treatment is often continued while the patient is in the coronary care unit. In addition, some patients may be started on a $\beta$ blocker while in the coronary care unit, either to limit infarct size, ${ }^{1314}$ or for angina pectoris. Stopping such treatment before exercise testing is hazardous, particularly after myocardial infarction, because of the risk of a rebound effect. ${ }^{13}$ As a result many patients perform their pre-discharge post-infarct exercise tests while they are taking $\beta$ blockers. Until now the impact of $\beta$ blockade on the results of pre-discharge exercise testing had not been studied.

In the current study the sensitivity of pre-discharge exercise testing in detecting multivessel disease was lower in patients taking $\beta$ blockers $(76 \%$ ) than in those who were not $(95 \%)$. Our data seem to be at variance with those of Marcomichelakis et al, who studied patients with suspected coronary disease who had not suffered an infarct before and after the introduction of $\beta$ blockade. ${ }^{9}$ They found that oxpren-

CORONARY ARTERIOGRAPHY

125

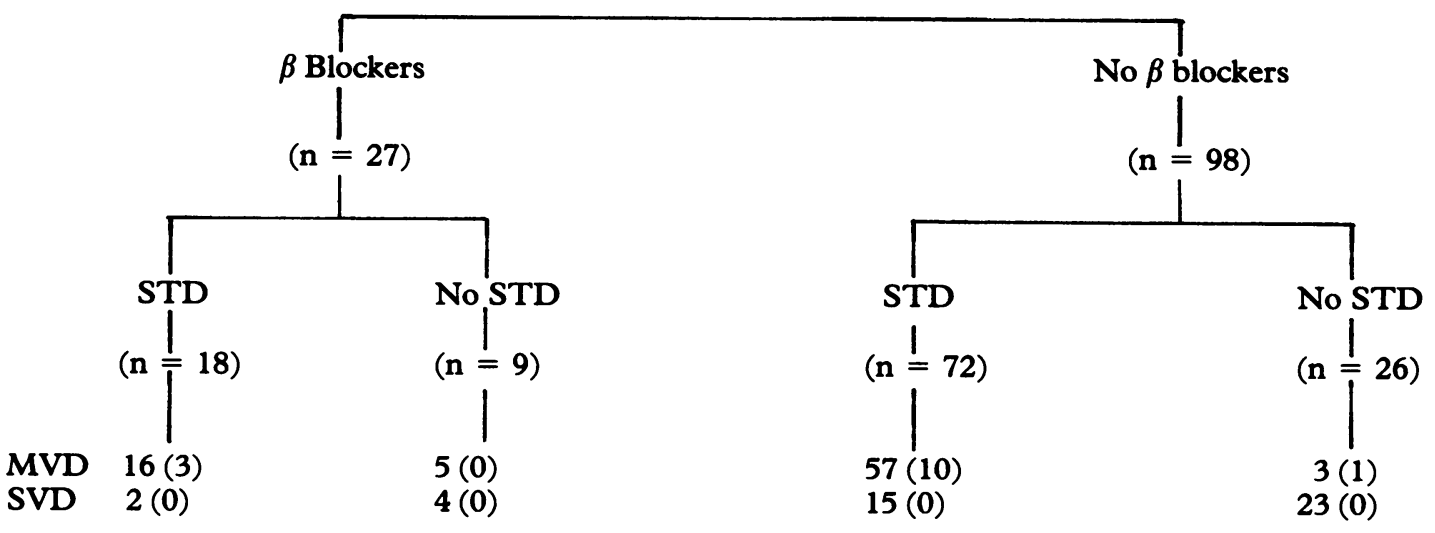

Figure Ability of ST depression induced by exercise testing to predict multivessel disease and major complications (death or reinfarction) when patients were subdivided on the basis of treatment with $\beta$ blockers at the time of exercise. (Numbers in parentheses are those who died or reinfarcted.) MVD, multivessel disease; $S V D$, single vessel disease; $S T D, S T$ depression on exercise testing. 
olol increased the specificity of the exercise test, abolishing some false positive results, without reducing the sensitivity. No patient with coronary artery disease and a positive exercise test before treatment with $\beta$ blockers had a negative test when oxprenolol was introduced. However, two factors should be noted when these results are compared with ours. In the study by Marcomichelakis et al the patients performed symptom limited exercise tests and in these patients treatment with $\beta$ blocker did delay the onset of ST depression. ${ }^{9}$ In the current study the patients performed submaximal exercise tests. Thus it is likely that the patients treated with $\beta$ blockers had a higher incidence of false negative exercise tests than those who were not treated with $\beta$ blockers. This is because $\beta$ blockade abolished or delayed the onset of ST depression. This is consistent with the results of both Fox et al ${ }^{8}$ and Ho et al. ${ }^{15}$ In these studies patients without a recent history of myocardial infarction performed maximal exercise tests on and off $\beta$ blockers. In both studies $\beta$ blockade was associated with increased exercise duration and delay in onset of ST depression. In the study by Ho et al 14 patients with ST depression before $\beta$ blockade developed equivocal tests while they were treated with $\beta$ blockers. Fox et al found that 16 patients had complete and 16 had incomplete abolition of exercise induced ST depression when they were treated with $\beta$ blockers. Thus it seems that on symptom limited exercise testing $\beta$ blockade can abolish false positive exercise tests and reduce or delay the onset of ST depression in patients with multivessel disease. These data are consistent with our arteriographic data which showed a higher incidence of false negative tests in patients treated with $\beta$ blockers $(19 \%)$ than in those who were not $(3 \%)$. It seems likely that $\beta$ blockade prevented the development of ST depression on exercise in some of our patients.

The presence of $\beta$ blockade at the time of exercise testing did not seem to limit the ability of the test to identify those patients who were at risk of subsequent cardiac events. When all cardiac events were grouped together, exercise testing was equally sensitive in identifying patients at risk of subsequent cardiac events in patients treated with $\beta$ blockers and those who were not. This also appeared to be true when cardiac events were studied individually. However, the number of events in each category is small and as a result the confidence intervals are wide. As far as we know the influence of $\beta$ blockade on the prognostic implications of pre-discharge exercise testing has not been evaluated before.

Why did $\beta$ blockade seem to have a different effect on the ability of exercise testing to predict coronary anatomy than it did on the ability of the test to predict prognosis? This question is important because multivessel disease is recognised as one of the most useful predictors of prognosis after myocardial in $\div$ farction. It may be that although multivessel disease. does imply increased risk after infarction, it is still $\frac{1}{8}$ non-specific marker. ${ }^{16}$ In the current study a large proportion of such patients had no subsequench. cardiac event during the follow up period. Thi finding is consistent with the results of the Coronar 9 Artery Surgery Study ${ }^{18}$ and with the data of workers who studied the prognostic importance of multivessel disease after acute myocardial infarction. ${ }^{16-18} \mathrm{It}$ is well recognised that the patients with the worst prognosis after acute myocardial infarction are those with severe left ventricular dysfunction who are unable to perform a pre-discharge exercise test. ${ }^{4} 8$ Among patients with preserved left ventricular funco tion who are able to perform an exercise test it seem $\mathbf{S}$ likely that those with most severe ischaemia op exercise testing, in addition to those with multivesseP disease, are also the group who are at greatest risk o $\vec{f}$ subsequent cardiac events. Given that $\beta$ blockade cap delay or abolish myocardial ischaemia, as manifest b ST segment depression on exercise, it is also probable that exercise induced ST depression will be abolished in those with least severe ischaemia, even it they have multivessel disease. In contrast, if exercis\& induced ischaemia is so severe that it is not abolished by $\beta$ blockade, it seems reasonable to expect that such a patient would have a high risk of subsequent cardiae events. Thus $\beta$ blockade may in fact have filtered oud patients with less severe ischaemia on exercise. It was to be expected, therefore, that while $\beta$ blockade might decrease the accuracy of submaximal exercise testing in identifying patients with multivessel dis ease it was less likely to reduce the ability of the test tof identify patients at risk of subsequent cardiac events This is borne out by the fact that none of the patients treated with $\beta$ blockers who had negative exercisê. tests and multivessel disease died or reinfarcted.

\section{CLINICAL IMPLICATIONS}

These data have important implications for the assessment of patients after myocardial infarction. It seems that $\beta$ blockade reduces the ability of pre discharge exercise testing to identify patients with multivessel disease. Despite this effect the test does not seem to lose its prognostic powers and is still able to identify patients at risk of subsequent cardiato events. Since this is the chief reason for performing the test we feel that it is not necessary to sto treatment with $\beta$ blockers before pre-discharge exer̂́ cise testing of patients who have had an acute myocardial infarction.

\section{References}

1 Mannering D, Bennett ED, Ward DE, et al. Accurate detection of triple vessel disease in patients wit exercise induced ST segment depression after infarç 

tion. Br Heart J 1987;57:133-8.

2 Schwartz KM, Turner JD, Sheffield LT, et al. Limited exercise testing soon after myocardial infarction. Ann Intern Med 1981;94:727-34.

3 Fuller CM; Raiznner AE, Verani MS, et al. Early post myocardial infarction treadmill stress testing. Ann Intern Med 1981;94:734-9.

4 Murray DP, Salih M, Tan LB, Murray RG, Littler WA. Prognostic stratification of patients after myocardial infarction. Br Heart J 1987;57:313-8.

5 Theroux P, Waters DD, Halphen C, Debaiseux JC, Mizgala HF. Prognostic value of exercise testing soon after myocardial infarction. $N$ Engl $J$ Med 1979;301:341-5.

6 DeBusk RF, Kraemer HC, Nash E. Stepwise risk stratification soon after myocardial infarction. Am J Cardiol 1983;52:1161-6.

7 Le Winter MM, Crawford MH, O'Rourke RA, Karliner JS. The effects of oral propranalol, digoxin and combination therapy on the resting and exercise electrocardiogram. Am Heart J 1977;93:202-9.

8 Fox K, Selwyn A, Oakley D, Jonathan A, Shillingford J. Praecordial surface mapping after exercise in evaluation of propranolol for angina pectoris. $\mathrm{Br}$ Heart J 1980;43:376-81.

9 Marcomichelakis J, Donaldson R, Green J, et al. Exercise testing after beta-blockade: improved specificity and predictive value in detecting coronary heart disease. Br Heart J 1980;43:252-61.

10 Madias J, Chajine R, Gibson R, Blocklow D. A comparison of transmural and nontransmural acute myocardial infarction. Circulation 1974;49:498-506.
11 Naughton JP, Hellerstein HK. Exercise testing and exercise training in coronary heart disease. New York: Academic Press, 1973.

12 Odemuyiwa O, Peart I, Albers C, Hall R. Reciprocal ST depression in acute myocardial infarction. Br Heart $J$ 1985;54:479-83.

13 The MIAMI trial research group. Metoprolol in acute myocardial infarction. A randomized placebo-controlled international trial. Eur Heart J 1985;6: 199-226.

14 ISIS-1 Collaborative Study Group randomized trial of intravenous atenolol among 16027 cases of suspected acute myocardial infarction: ISIS-1. Lancet 1986; ii:57-66.

15 Ho SC, McMorish MJ, Taylor RR. Effect of betaadrenergic blockade on the results of exercise testing related to the extent of coronary artery disease. $\mathrm{Am} \mathrm{J}$ Cardiol 1985;55:258-62.

16 CASS Principal Investigators and their Associates. Coronary artery surgery study (CASS): a randomized trial of coronary artery surgery: survival data. Circulation 1983;66:939-48.

17 Murray DP, Rafiqi RG, Murray RG, Littler WA. Prognostic investigations after myocardial infarction: a comparison of radionuclide angiography and $\mathrm{Tl}^{201}$ scintigraphy. Eur J Nucl Med 1986 ;11:381-5.

18 Veenbrink Th WG, van der Werf $T$, Westerhof $P W$, Robles de Medina EO, Meijler FL. Is there an indication for coronary angiography in patients under 60 years of age with no or minimal angina pectoris after a first myocardial infarction? $\mathrm{Br}$ Heart $\mathrm{J}$ 1985;53:30-5. 